\title{
Influence of Seasonality and Sunlight Effects on Rollinia mucosa Leaves Fingerprint
}

\author{
Sabrina Afonso, ${ }^{a}$ Fabiano B. Silva, ${ }^{a}$ Gustavo G. Marcheafave, ${ }^{a}$ Pedro H. Hatumura, ${ }^{a}$ \\ Roy E. Bruns ${ }^{b}$ and Ieda S. Scarminio ${ }^{\circledR} * a$
}

\author{
${ }^{a}$ Laboratório de Quimiometria em Ciências Naturais, Departamento de Química, \\ Universidade Estadual de Londrina, Rodovia Celso Garcia Cid, PR 445, km 380, \\ 86051-980 Londrina-PR, Brazil \\ ${ }^{b}$ Instituto de Química, Universidade Estadual de Campinas, \\ CP 6154, 13083-970 Campinas-SP, Brazil
}

\begin{abstract}
Rollinia mисоsa fruit has generated great interest due to the presence of bioactive compounds, which exhibit promising biological activities. Fingerprinting analytical techniques, chromatographic-diode array detection (DAD), infrared, mass spectrometric, ${ }^{1} \mathrm{H}$ and ${ }^{13} \mathrm{C}$ nuclear magnetic resonance (NMR) spectra, associated with chemometric analysis and mixture design, were used to determine chemical discriminations of sun-exposed and self-shaded leaves of Rollinia mucosa in each of the four seasons. Sunlit leaves in winter presented higher metabolite signals related to the acetogenins, whereas shaded leaves have higher abundances of carbohydrates and terpenes. Sunlit leaves harvested in the summer had the smallest metabolite abundances. Fingerprints confirmed the presence of two acetogenins, annonacin A and annonastatin. Ternary and quaternary mixtures of the statistical mixture design were most effective for revealing important discriminations.
\end{abstract}

Keywords: Rollinia mucosa, seasonal variation, leaves, sun exposed, self-shaded

\section{Introduction}

Rollinia mucosa is a tropical fruit tree indigenous to the West Indies and Central America, ${ }^{1}$ and popular fruit in Brazil, Mexico, Bolivia, Venezuela, among others. This plant family has generated great interest due to the presence of bioactive compounds, which exhibit promising biological activities, including anthelmintic, ${ }^{2}$ antifungal, ${ }^{3}$ antimalarial, ${ }^{4}$ antineoplastic, ${ }^{5}$ antimicrobial, ${ }^{6}$ antiprotozoal ${ }^{7}$ and larvicidal ${ }^{8}$ properties, as well as being toxic to tumor cells, ${ }^{9,10}$ among others. Known as a medicinal tree, the different parts of the plant such as the roots, stems, bark, seeds and leaves have been explored. Pharmacological and phytochemical studies of this species reported the presence of major active principles, acetogenins, ${ }^{11-13}$ that are known to have anticancer activities. Generally, these complex molecules present terminal $\gamma$-lactone ring units, tetrahydrofuran (THF) units along the aliphatic chain and other functional groups. ${ }^{14}$

The environmental factors such as temperature, humidity, seasonality, ${ }^{15}$ circadian rhythm, ${ }^{16}$ ultraviolet radiation, ${ }^{17}$ air

*e-mail: ieda@uel.br pollution and other external conditions affect both the quantitative and qualitative composition of metabolites. ${ }^{18}$ Sunlit and shaded leaves of plants differ structurally and therefore adapt to sunlight at different levels. ${ }^{19}$ Besides being sensitive to different light accessibility conditions, metabolites in leaves have varying compositions during the year. ${ }^{20-22}$ They represent many distinct compound classes with different solubilities, polarities and quantities. As the active constituents are not constant throughout the year, the timing of plant harvesting becomes important..$^{20}$ Such variation substantially changes the quality, activity properties and secondary metabolite production, affecting the quality of plants used in pharmaceutical, industrial and nutritional applications.

Metabolic fingerprinting has been increasingly used to provide information for the study of vegetal material to simultaneously analyze several metabolites, identify differences among them, classify samples and identify discriminating constituents based on spectral characteristics. A variety of appropriate analytical fingerprinting techniques are used for this, the two main ones being nuclear magnetic resonance ( ${ }^{1} \mathrm{H}$ NMR) spectroscopy ${ }^{23,24}$ and mass spectrometry (MS). ${ }^{25}$ Fourier transform 
infrared spectroscopy (FTIR), ${ }^{26}$ high performance liquid chromatography (HPLC), ${ }^{27,28}$ liquid chromatography (LC), gas chromatography (GC) and UV-Vis spectroscopy ${ }^{29}$ have also been used. Infrared spectroscopy is important because it can be used for simultaneously analyzing several hundred metabolites in order to obtain information about the functional groups present as well as the relative changes in their quantities. Analytical fingerprinting techniques allied with chemometric methods have been very successful for the analysis of complex mixtures such as those found in vegetal species.

Extraction is probably the most critical step in metabolomics. Therefore, several solvents and extraction methods should be tested and compared between the groups of samples. Our research group has used statistical mixture designs for the development of fingerprint profiles for extracted metabolites of plant material. ${ }^{29-34}$ This procedure is important because the extraction conditions differ greatly for different types of metabolomic compounds. The choice of solvents involves compromise between maximizing the efficiency of the interactions between molecules while insuring the extraction of an expressive number of metabolites depending on the case under study. ${ }^{35}$

Although it is important to know the effect of light accessibility and seasonal changes on the chemical composition of plants used in pharmaceuticals, industrial and nutritional applications, few studies have been found in the literature addressing the two aspects together. Therefore, the objective of this work was to explore how the seasonal changes and light accessibility affects the chemical composition of Rollinia mucosa leaves by chromatographic and spectroscopy fingerprint technique. A mixture design with five solvents having different properties was used to obtain fingerprints with maximum information.

\section{Experimental}

\section{Plant material}

Leaves were collected between April 2011 and March 2012 in Universidade Estadual de Londrina (UEL), Londrina, PR, Brazil. The collections were made in April/May/June 2011 (autumn), July/August/September 2011 (winter), October/November/December 2011 (spring) and January/February/March 2012 (summer). The collections occurred weekly in the morning. The leaves were collected in two layers in the crown of the tree. Leaves in the upper layer receiving direct sunlight were classified as sun-exposed, while those in the lower layer were considered self-shaded. A voucher specimen
Rollinia тисоsa grown under different sunlight conditions (sun-exposed FUEL 49.286 and self-shaded FUEL 49.287) have been stored in the Herbarium of the UEL. Drying was carried out at about $27^{\circ} \mathrm{C}$ for nine days.

\section{Reagents}

HPLC grade acetonitrile and methanol were purchased from LiChrosolv. Mobile phase mixture preparations were made using water prepared with the Millipore Milli-Q purification system. Ethanol, ethyl acetate, dichloromethane, acetone, and chloroform were purchased from FMaia. All chemicals were of analytical grade. For mass spectrometric analysis, $85 \%$ formic acid and LC-MS purity methanol were purchased from Sigma-Aldrich. Deuterated dimethyl sulfoxide (DMSO- $d_{6}, 99.9 \%$ of deuterium) was purchased from Sigma-Aldrich.

\section{Extract preparation}

Extraction mediums were prepared using mixtures of five components: ethanol (e), ethyl acetate (a), dichloromethane (d), acetone (A), and chloroform (c), whose proportions were specified by a simplex centroid design. ${ }^{36}$ The solvent proportions used in the extraction mixtures are specified in Table 1. Thirty-three extractions were carried out with 31 different mixtures and two other runs were performed at the center point. Each extract was prepared by weighing $2 \mathrm{~g}$ of dried and crushed leaves and adding $15 \mathrm{~mL}$ of the solvent mixtures in Table 1 . These mixtures were then placed in an ultrasonic bath (Unique, model USC 1400) for $60 \mathrm{~min}$ with the bathwater being changed every $30 \mathrm{~min}$ to avoid heating. The extracts were filtered through filter paper to separate the solution from small pieces of leaves and the solution was placed in an identified and weighed flask. This procedure was repeated fourteen more times, so the total volume of solvent mixture added to the leaves was $225 \mathrm{~mL}$. The remainder was evaporated in a rotary evaporator, removing all the solvent still present in the sample, until attaining constant weight. ${ }^{31,37}$

\section{HPLC analysis}

$3.0 \mathrm{mg}$ of the crude extract were dissolved in $1.0 \mathrm{~mL}$ of methanol. Twenty microliters of this extract were added to $10 \mathrm{~mL}$ of the mobile phase $(35 \%$ methanol, $35 \%$ acetonitrile, $30 \%$ water). Then the samples were filtered through a $0.20 \mu \mathrm{m}$ Chromafil filter and analyzed immediately. The chromatographic conditions were: Phenomenex C18 Kinetex $2.6 \mu \mathrm{m} 100 \AA$ Å column, with 
Table 1. Simplex centroid design solvent proportions used in the extractions

\begin{tabular}{|c|c|c|c|c|c|c|}
\hline & \multirow{2}{*}{ Sample } & \multicolumn{5}{|c|}{ Solvent extractor } \\
\hline & & $\mathrm{e}$ & $\mathrm{a}$ & $\mathrm{d}$ & A & $\mathrm{c}$ \\
\hline 1 & ethanol (e) & 1 & 0 & 0 & 0 & 0 \\
\hline 2 & ethyl acetate (a) & 0 & 1 & 0 & 0 & 0 \\
\hline 3 & dichloromethane (d) & 0 & 0 & 1 & 0 & 0 \\
\hline 4 & acetone (A) & 0 & 0 & 0 & 1 & 0 \\
\hline 5 & chloroform (c) & 0 & 0 & 0 & 0 & 1 \\
\hline 6 & e:a & $1 / 2$ & $1 / 2$ & 0 & 0 & 0 \\
\hline 7 & e:d & $1 / 2$ & 0 & $1 / 2$ & 0 & 0 \\
\hline 8 & $\mathrm{e}: \mathrm{A}$ & $1 / 2$ & 0 & 0 & $1 / 2$ & 0 \\
\hline 9 & $\mathrm{e}: \mathrm{c}$ & $1 / 2$ & 0 & 0 & 0 & $1 / 2$ \\
\hline 10 & $\mathrm{a}: \mathrm{d}$ & 0 & $1 / 2$ & $1 / 2$ & 0 & 0 \\
\hline 11 & $\mathrm{a}: \mathrm{A}$ & 0 & $1 / 2$ & 0 & $1 / 2$ & 0 \\
\hline 12 & $\mathrm{a}: \mathrm{c}$ & 0 & $1 / 2$ & 0 & 0 & $1 / 2$ \\
\hline 13 & $\mathrm{~d}: \mathrm{A}$ & 0 & 0 & $1 / 2$ & $1 / 2$ & 0 \\
\hline 14 & A:c & 0 & 0 & 0 & $1 / 2$ & $1 / 2$ \\
\hline 15 & $\mathrm{~d}: \mathrm{c}$ & 0 & 0 & $1 / 2$ & 0 & $1 / 2$ \\
\hline 16 & e:a:d & $1 / 3$ & $1 / 3$ & $1 / 3$ & 0 & 0 \\
\hline 17 & e:A:c & $1 / 3$ & 0 & 0 & $1 / 3$ & $1 / 3$ \\
\hline 18 & e:a:c & $1 / 3$ & $1 / 3$ & 0 & 0 & $1 / 3$ \\
\hline 19 & e:d:c & $1 / 3$ & 0 & $1 / 3$ & 0 & $1 / 3$ \\
\hline 20 & e:a:A & $1 / 3$ & $1 / 3$ & 0 & $1 / 3$ & 0 \\
\hline 21 & $\mathrm{~d}: \mathrm{A}: \mathrm{c}$ & 0 & 0 & $1 / 3$ & $1 / 3$ & $1 / 3$ \\
\hline 22 & $\mathrm{a}: \mathrm{A}: \mathrm{c}$ & 0 & $1 / 3$ & 0 & $1 / 3$ & $1 / 3$ \\
\hline 23 & $\mathrm{a}: \mathrm{d}: \mathrm{c}$ & 0 & $1 / 3$ & $1 / 3$ & 0 & $1 / 3$ \\
\hline 24 & a:d:A & 0 & $1 / 3$ & $1 / 3$ & $1 / 3$ & 0 \\
\hline 25 & e:d:A & $1 / 3$ & 0 & $1 / 3$ & $1 / 3$ & 0 \\
\hline 26 & e:a:d:A & $1 / 4$ & $1 / 4$ & $1 / 4$ & $1 / 4$ & 0 \\
\hline 27 & a:d:A:c & 0 & $1 / 4$ & $1 / 4$ & $1 / 4$ & $1 / 4$ \\
\hline 28 & e:d:A:c & $1 / 4$ & 0 & $1 / 4$ & $1 / 4$ & $1 / 4$ \\
\hline 29 & e:a:A:c & $1 / 4$ & $1 / 4$ & 0 & $1 / 4$ & $1 / 4$ \\
\hline 30 & e:a:d:c & $1 / 4$ & $1 / 4$ & $1 / 4$ & 0 & $1 / 4$ \\
\hline 31 & e:a:d:A:c & $1 / 5$ & $1 / 5$ & $1 / 5$ & $1 / 5$ & $1 / 5$ \\
\hline
\end{tabular}

dimensions of $100 \times 4.6 \mathrm{~mm}, 20 \mu \mathrm{L}$ injection volume and $1.0 \mathrm{~mL} \mathrm{~min}^{-1}$ mobile phase flow rate. HPLC analysis was conducted on a Finnigan Surveyour liquid chromatograph equipped with a Finnigan Surveyour PDA Plus diode array detector (DAD). Elution was monitored at the 210, 220 and $280 \mathrm{~nm}$ wavelengths. The runs were carried out in random order including triplicates for the design center point experiments. The data were processed using ChromQuest 4.2 software. Satisfactory separation was achieved in $15 \mathrm{~min}$.

\section{ATR-FTIR analysis}

For FTIR analysis, a Thermo Scientific FT-IR Nicolet iS 10 spectrophotometer was used. The crude extracts were analyzed directly on a germanium crystal in the attenuated total reflection (ATR) mode. The spectra were recorded in the $4000-675 \mathrm{~cm}^{-1}$ region, with $4 \mathrm{~cm}^{-1}$ resolution and 32 scans.

NMR analysis

${ }^{1} \mathrm{H}$ NMR analyses were performed at $298 \mathrm{~K}$ on a Bruker Avance III 400 spectrometer equipped with a $5 \mathrm{~mm}$ BBI probe, for ${ }^{1} \mathrm{H}$ and ${ }^{13} \mathrm{C}$ spectra. $80 \mathrm{mg}$ of crude extract were weighed and $0.50 \mathrm{~mL}$ of DMSO- $d_{6}$ solvent was added. The acquisition parameters for ${ }^{1} \mathrm{H}$ were as follows: number of data points 65,536; spectral width $8,012 \mathrm{~Hz}$; acquisition time $4.000 \mathrm{~s}$; delay time $1.0 \mathrm{~s}$; and number of scans 128 . The parameters of ${ }^{13} \mathrm{C}$ NMR spectrum used for the assignments were as follows: number of data points, 32,768; spectral width, 24,038 Hz; acquisition time, $1.363 \mathrm{~s}$; delay time, $2.0 \mathrm{~s}$; number of scans, 9,216.

\section{MS analysis}

Samples were prepared by weighing $3.0 \mathrm{mg}$ of crude extract dissolved in $1.0 \mathrm{~mL}$ of MS purity methanol. This solution was diluted in ethanol with $1 \%$ formic acid and then further diluted to obtain a solution concentration of $1 \times 10^{-6} \mathrm{mg} \mathrm{mL}^{-1}$. The diluted extract solution was infused into the Bruker quadrupole mass spectrometer, fitted with electrospray ionization (ESI). The analysis was performed in the positive mode. An $\mathrm{m} / \mathrm{z}$ scan range from 80 to $1000 \mathrm{Da}$ was chosen and the ionization conditions were: $3 \mathrm{kV}$ capillary voltage, $150{ }^{\circ} \mathrm{C}$ source temperature, $80 \mathrm{~L} \mathrm{~h}^{-1}$ cone gas flow, $800 \mathrm{~L} \mathrm{~h}^{-1}$ desolvation gas flow and $350{ }^{\circ} \mathrm{C}$ desolvation temperature. Nitrogen gas used in the nebulization was $99 \%$ pure. The data were processed using the software v4.1 MassLynx.

\section{Results and Discussion}

To evaluate whether the chromatographic fingerprints allow discrimination of sun-exposed and self-shaded leaves in winter and summer, the chromatographic data were submitted to factor analysis. The chromatograms were arranged in a matrix of 1800 rows and 66 columns, where each row represents absorbance in arbitrary units at each retention time, and the columns the extracts prepared according to the statistical mixture design (33 extracts for each type of leaf). The Statistica version $6.0^{38}$ was used 
to perform the factor analysis. The data variables were centered on the means. The first five factors explain 95.87 and $84.64 \%$ of the total variance of the data for the samples collected in winter and summer, respectively. Although the fifth factor has low variance, it brings relevant chemical information in the form of the chemical species presenting sample discrimination.

Figure 1 shows the score plot of the first and fifth factors for the extracts of sun-exposed and self-shaded leaves collected in winter. The inspection of the score plot shows that most of the extracts of leaves exposed to the sun are located in the positive region of factor 5, while the extracts of self-shaded leaves are located in the negative region. Of the 31 statistical design mixtures, all the pure solvents and their binary mixtures did not result in discrimination of the sun-exposed and selfshaded leaves. Only extracts prepared with ternary mixtures of ethanol:ethyl acetate:dichloromethane (ead) and ethyl acetate:acetone:chloroform (aAc), and quaternary mixtures of ethanol:ethyl acetate:di chloromethane:chloroform (eadc) and ethanol:ethyl acetate:dichloromethane:acetone (eadA) showed good discrimination of these leaves.

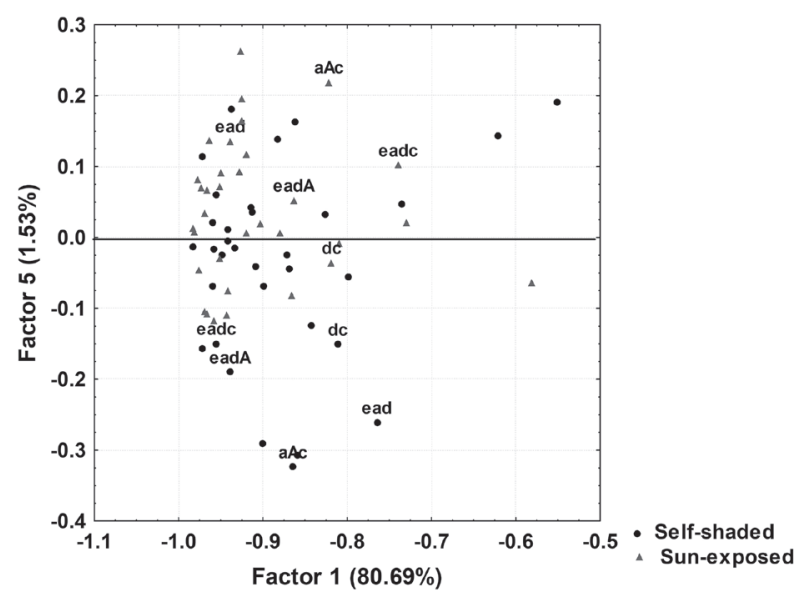

Figure 1. Factor analysis score plot of the chromatograms of extracts for the mixture design of the self-shaded and sun-exposed Rollinia mucosa leaves collected in the winter. ead: ethanol:ethyl acetate:dichloromethane; aAc: ethyl acetate:acetone:chloroform; dc: dichloromethane:chloroform; eadc: ethanol:ethyl acetate:dichlorom ethane:chloroform; eadA: ethanol:ethyl acetate:dichloromethane:acetone.

The inspection of the loadings on factor 5 , shown in Figure 2a, suggests that separation occurs owing to five metabolites. Metabolites with retention times of $0.90,1.22$ and $1.40 \mathrm{~min}$ can be correlated with the more positive factor 5 score extracts, corresponding to the sun-exposed leaf extracts of aAc, ead, eadc and eadA. Metabolites with retention times of 1.86 and $2.57 \mathrm{~min}$ are associated with the more negative factor 5 score extracts and the self- shaded leaves (aAc, ead, eadc and eadA). Figures $2 b-2 f$ show the DAD spectra for these chromatographic retention times.

In the summer (Figure 3a), the score plot shows that the extracts prepared in the dichloromethane:chloroform (dc) mixture are the most divergent when compared to the others. By removing these extracts from the data matrix (Figure 3b), a more homogeneous separation of the sun-exposed and self-shaded extracts relative to those of winter is obtained. This result suggests that extracts prepared in ternary and quaternary mixtures are more efficient for their discrimination. As such, analysis using statistical mixture designs is useful for revealing the compositional differences of bioactive compounds in both summer and winter.

Figure 4a shows the factor 5 loadings for the samples collected in the summer. There are nine peaks of greater weight in the extract discrimination, against five for the samples collected in the winter. The sun-exposed extracts are mostly in the factor 5 negative region and have the three largest weight profiles in the discrimination process (with retention times in $0.94,1.86$ and $2.65 \mathrm{~min}$ ), whereas there are a higher number of peaks with positive loadings $(0.85,1.22,1.40,1.74,2.57$ and $3.00 \mathrm{~min})$ associated with the shaded samples. As such the samples collected in the summer showed greater metabolite diversity compared with those of winter. Figures $4 \mathrm{~b}-4 \mathrm{j}$ show the UV-DAD spectra for these chromatographic retention times.

These results show a more complicated pattern than might be expected. The compound(s) with a $1.40 \mathrm{~min}$ retention time indicates greater metabolite abundances for the sun-exposed leaves in the winter, but for the shaded ones in the summer. A similar behavior occurs for the $1.86 \mathrm{~min}$ retention time compounds with greater abundances for sun-exposed samples in the summer and for the shaded samples in the winter. The pattern for the $2.57 \mathrm{~min}$ retention time compound(s) is less complicated. Its greater relative abundance for the shaded samples occurs in both summer and winter.

The UV-DAD spectra corresponding to each of these peaks of the loading plot are included in Figures 2 and 4. These spectra have maximum absorbances between 200 and $215 \mathrm{~nm}$, which are attributed to acetogenins due to the ester group present in the $\gamma$-lactones..$^{39}$ Methyl- $\gamma$-lactone is characteristic of all the acetogenins of Annonaceae and the presence of this group can be evidenced by IR and NMR spectroscopies.

The molecular fragments of acetogenin compounds (aldehydes, ketones, acids, esters and amides) are considered to be functional groups and can be detected by FTIR analysis. The IR spectrum also allows confirmation 

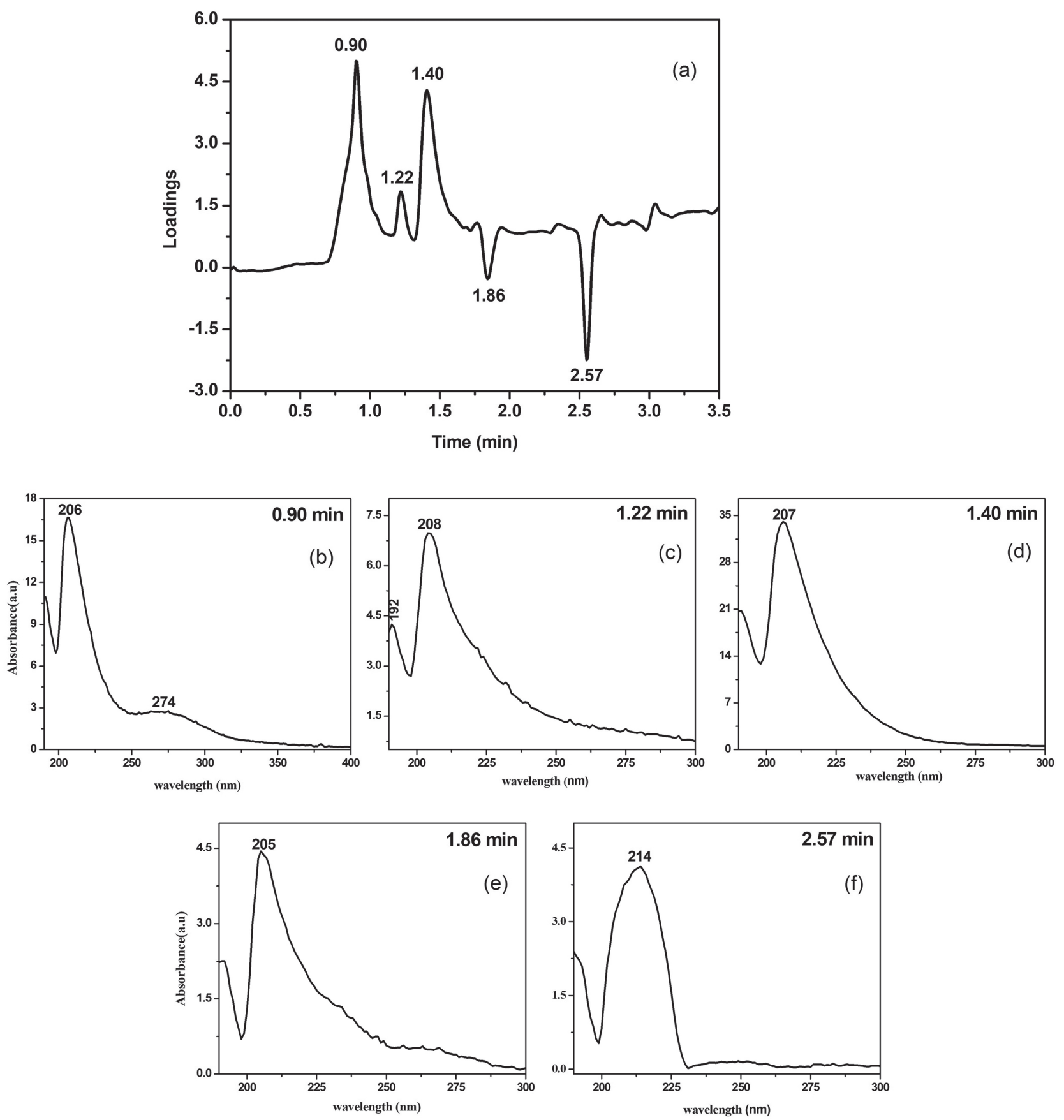

Figure 2. (a) Factor 5 factor analysis loadings for chromatograms of Rollinia mucosa self-shaded and sun-exposed leaves collected in the winter; (b-f) UV-DAD spectra for retention times present in loadings.

and characterization of an unsaturated $\gamma$-lactone indicated by a strong carbonyl absorption band at $1740-1750 \mathrm{~cm}^{-1}$, while that the saturated $\gamma$-lactone appears at about $1770 \mathrm{~cm}^{-1} .^{40}$ Therefore, infrared spectroscopic metabolic fingerprinting of extracts also was investigated for sun-exposed and self-shaded leaves collected in the four seasons. Factor analysis was performed on the entire infrared spectrum using an array of 1725 variables for 66 samples (extracts obtained by the mixture design of sun-exposed and self-shaded leaves) for four data sets (spring, summer, autumn and winter). The first four factors of the spring, summer, autumn and winter data have accumulated variances of 99.27, 99.36, 99.61 and $99.77 \%$, respectively. When analyzing the score plots for the four seasons, the summer and autumn show a similar profile, and surprisingly, the winter profile was similar to the one for the spring. For this reason we will discuss the results of the summer and winter data. 

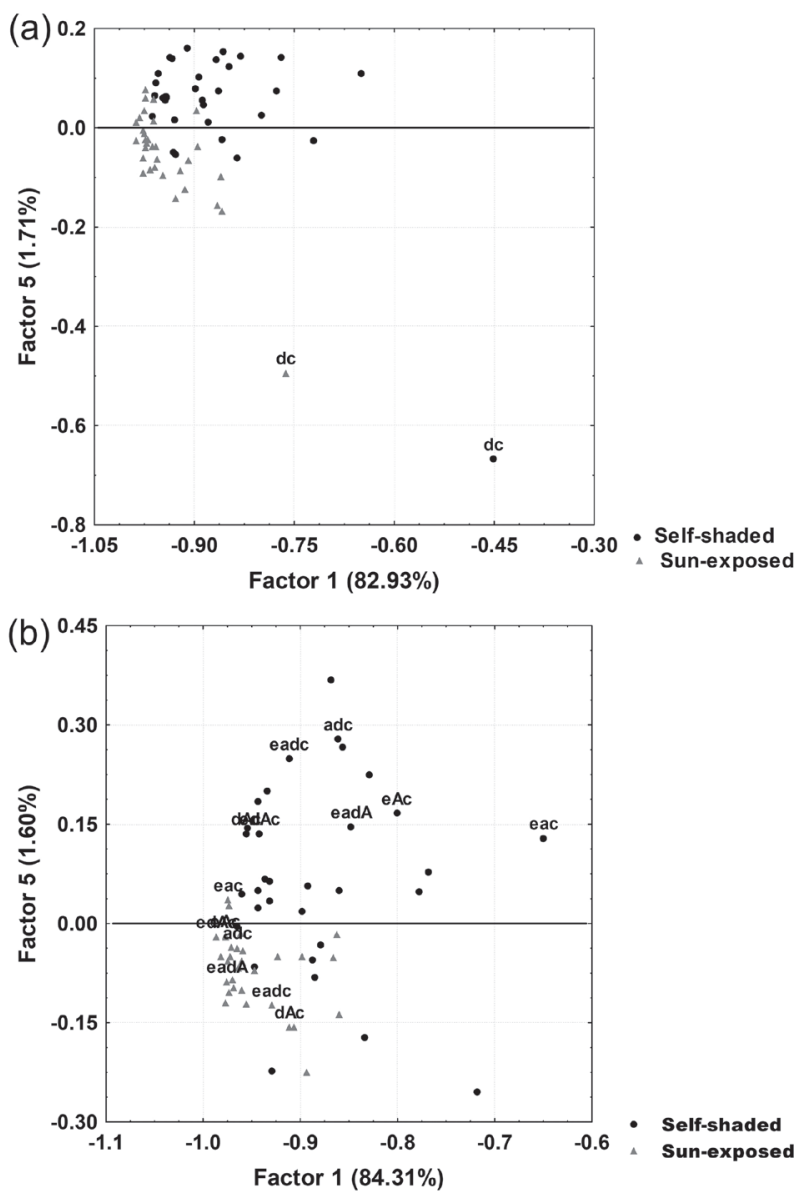

Figure 3. (a) Factor analysis score plot of the chromatograms of the experimental design extracts of Rollinia mucosa self-shaded and sun-exposed leaves collected in summer; (b) factor analysis score plot of these chromatograms after removal of the dc extracts. dc: dichloromethane:chloroform; adc: ethyl acetate:dichloromethane: chloroform; eAc: ethanol:acetone:chloroform; eac: ethanol:ethyl acetate: chloroform; dAc: dichloromethane:acetone:chloroform; eadc: ethanol:ethyl acetate:dichloromethane:chloroform; eadA: ethanol:ethyl acetate:dichloromethane:acetone.

Figures $5 \mathrm{a}$ and $5 \mathrm{~b}$ show the score plots for the winter and summer seasons. As for the chromatographic data, infrared spectra showed best discrimination due to sunlight accessibility received by the leaves throughout the four seasons. For the eadc extracts, the separation is more effective in samples from leaves collected in summer (Figure 5b) than winter. The leaf samples exposed to sunlight are positioned at more positive factor 3 scores, indicating that the incidence of solar radiation influences the production and/or quantity of plant metabolites for both seasons.

The loading plots for factors 3 and 4 (Figures 6a and 6b) show the wave number regions with the greatest impact on this sample separation. Figure 6a reveals that the bands of factor 4 discriminating sun-exposed and selfshaded extracts are $1758 \mathrm{~cm}^{-1}(\mathrm{vC}=\mathrm{O}), 2850$ and $2920 \mathrm{~cm}^{-1}$ $(\mathrm{vC}-\mathrm{H})$ in the winter. Figure $6 \mathrm{~b}$ shows that for the summer there is a good separation between sun-exposed and selfshaded extracts with higher weights for discrimination of these samples by the bands at $1061 \mathrm{~cm}^{-1}(\mathrm{vC}-\mathrm{O})$, $1755 \mathrm{~cm}^{-1}(\mathrm{vC}=\mathrm{O}), 2850$ and $2920 \mathrm{~cm}^{-1}(\mathrm{vC}-\mathrm{H})$ and $3312 \mathrm{~cm}^{-1}(\mathrm{vO}-\mathrm{H})$. These wavenumbers are characteristic of functional groups present in the acetogenins, and have greater impacts on the discrimination of sun-exposed leaf samples.

After obtaining the regions that showed the best discrimination of the sun-exposed and self-shaded leaves, the average of the infrared spectra of the five solvents that presented the highest discrimination were compared. Figure 7 illustrates seasonal concentration variations of some of the most important metabolites for sun-exposed and self-shaded leaves. Compared with the summer, the winter shows higher intensity bands near $1740-1770 \mathrm{~cm}^{-1}$ that are of interest for the identification of acetogenin compounds because they are related to carboxylic ester groups or fatty acid esters and the $\gamma$-lactone. ${ }^{41,42}$ Most characteristic bands associated with acetogenins are found, such as those for fatty and amino acids detected between $1500-1200 \mathrm{~cm}^{-1}$, monoterpenes detected at $840 \mathrm{~cm}^{-1}$ and the carbonyl group found in aldehydes, ketones, acids, esters and amides with absorption between 1650 and $1850 \mathrm{~cm}^{-1}$. Compared with the summer, the spring extracts show higher levels of glucose and fructose $\left(1060\right.$ and $1031 \mathrm{~cm}^{-1}$, respectively). ${ }^{43}$

Analysis of metabolites by NMR and mass spectrometry fingerprints was used to explore the presence of acetogenins in the extracts prepared with eadc quaternary mixture. Self-shaded leaves collected in the summer showed that the $[\mathrm{M}+\mathrm{Na}]^{+} \mathrm{m} / \mathrm{z} 619.46$ and 645.47 peaks can be assigned to the acetogenins annonacin $\mathrm{A}\left(\mathrm{C}_{35} \mathrm{H}_{64} \mathrm{O}_{7}\right)$ and annonastatin $\left(\mathrm{C}_{38} \mathrm{H}_{70} \mathrm{O}_{6}\right)$, which have calculated masses of 619.45 and 645.50 , respectively. ${ }^{40}$ The mass spectra also indicated the presence of other acetogenin compounds. However, only acetogenin annonacin A and annonastatin type structures were confirmed by the nuclear magnetic resonance fingerprint.

These acetogenins can be identified by their characteristic chemical shifts for the mono-tetrahydrofuran ring signals with two hydroxyls on adjacent carbons and $\alpha, \beta$-unsaturated carbons of the $\gamma$-lactone group that are consistent with the results obtained by the infrared spectroscopic analysis. Figure 8 shows the numbering scheme for the carbons of the THF and $\gamma$-lactone ring structures present in acetogenins used in the NMR data analysis. The presence of a ${ }^{1} \mathrm{H}$ NMR chemical shift at 3.82 and $3.84 \mathrm{ppm}$ and two ${ }^{13} \mathrm{C}$ NMR signals between 81 and $83 \mathrm{ppm}$ confirms the presence of the $\alpha, \alpha^{\prime}$-dihydroxylated tetrahydrofuran group of the acetogenins. 
Table 2 shows the ${ }^{13} \mathrm{C}$ NMR data characteristic of the structure of each acetogenin carbon atom that is not bonded to hydrogen, for comparison with the experimental data in the literature. ${ }^{40}$ The two carbon signals for the eadc extract
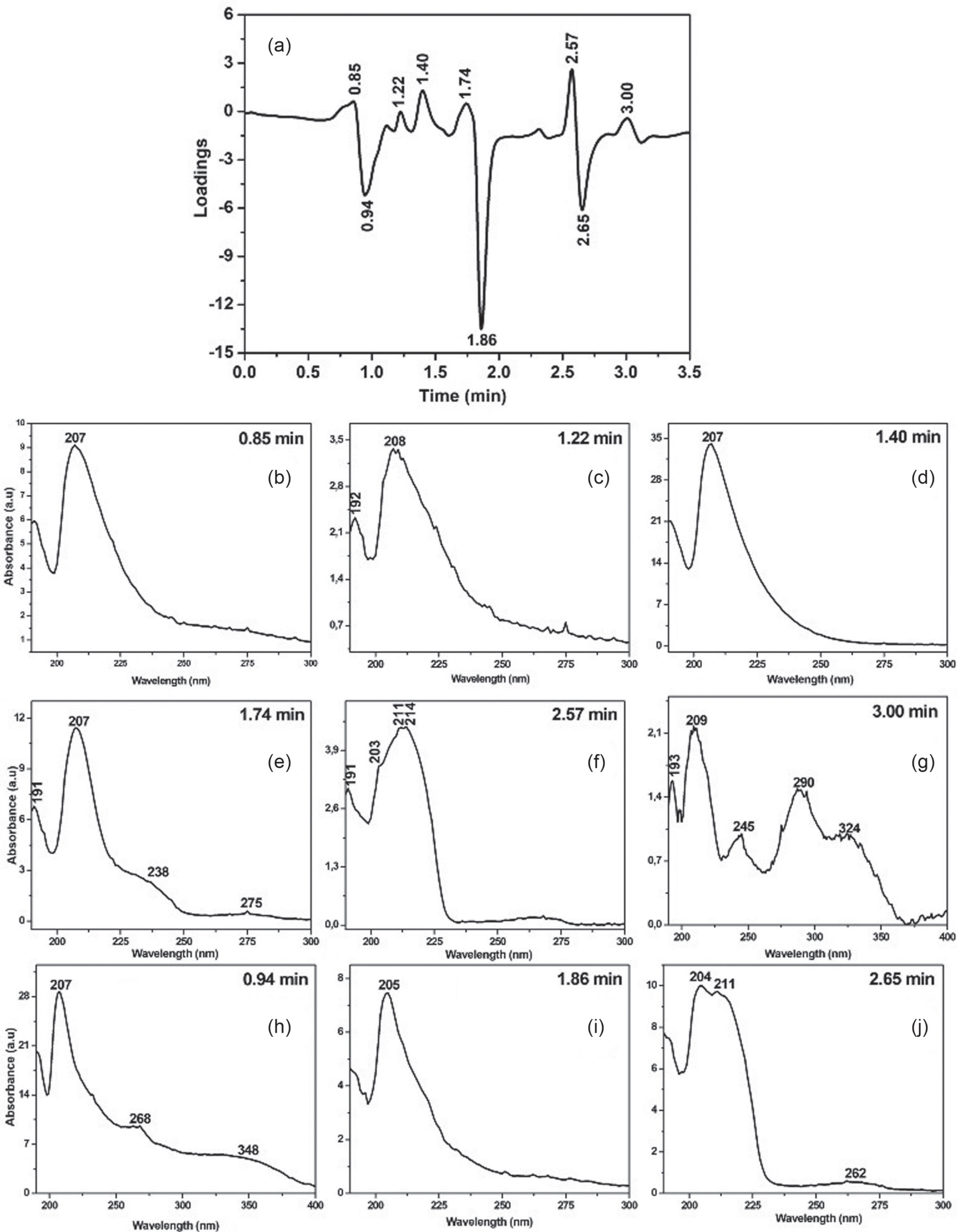

Figure 4. (a) Factor 5 loadings from factor analysis for chromatogram of Rollinia mucosa self-shaded and sun-exposed leaves collected in the summer; (b-j) UV-DAD spectra for retention times present in the loadings. 
are very close to the values reported for these carbons in positions 1 and 2 for annonacin A and annonastatin. Table 3

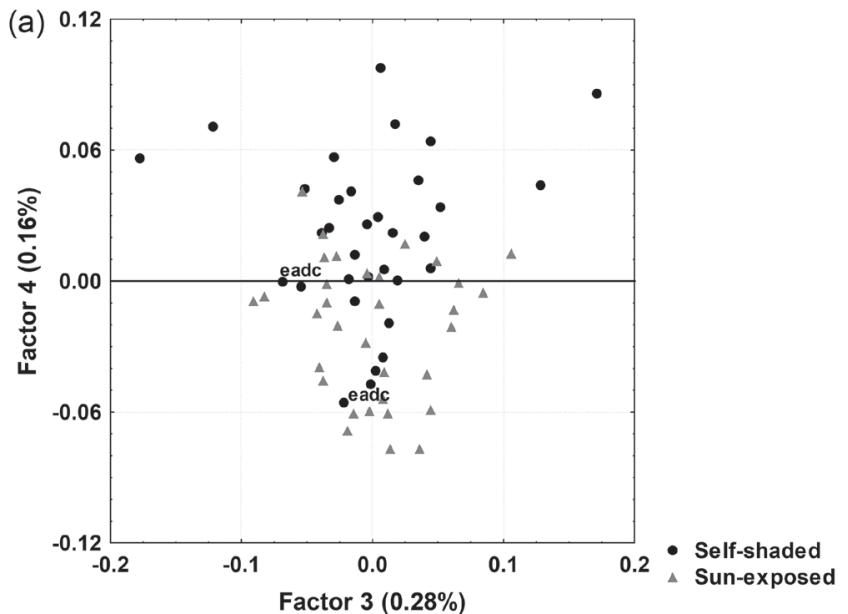

shows the heteronuclear multiple quantum correlation (HMQC) 2D NMR contour map data of the other carbon

Figure 5. Factor analysis score plot of infrared spectra of the experimental design extracts of self-shaded and sun-exposed Rollinia mucosa leaves collected in (a) winter and (b) summer. eadc: ethanol:ethyl acetate:dichloromethane:chloroform.
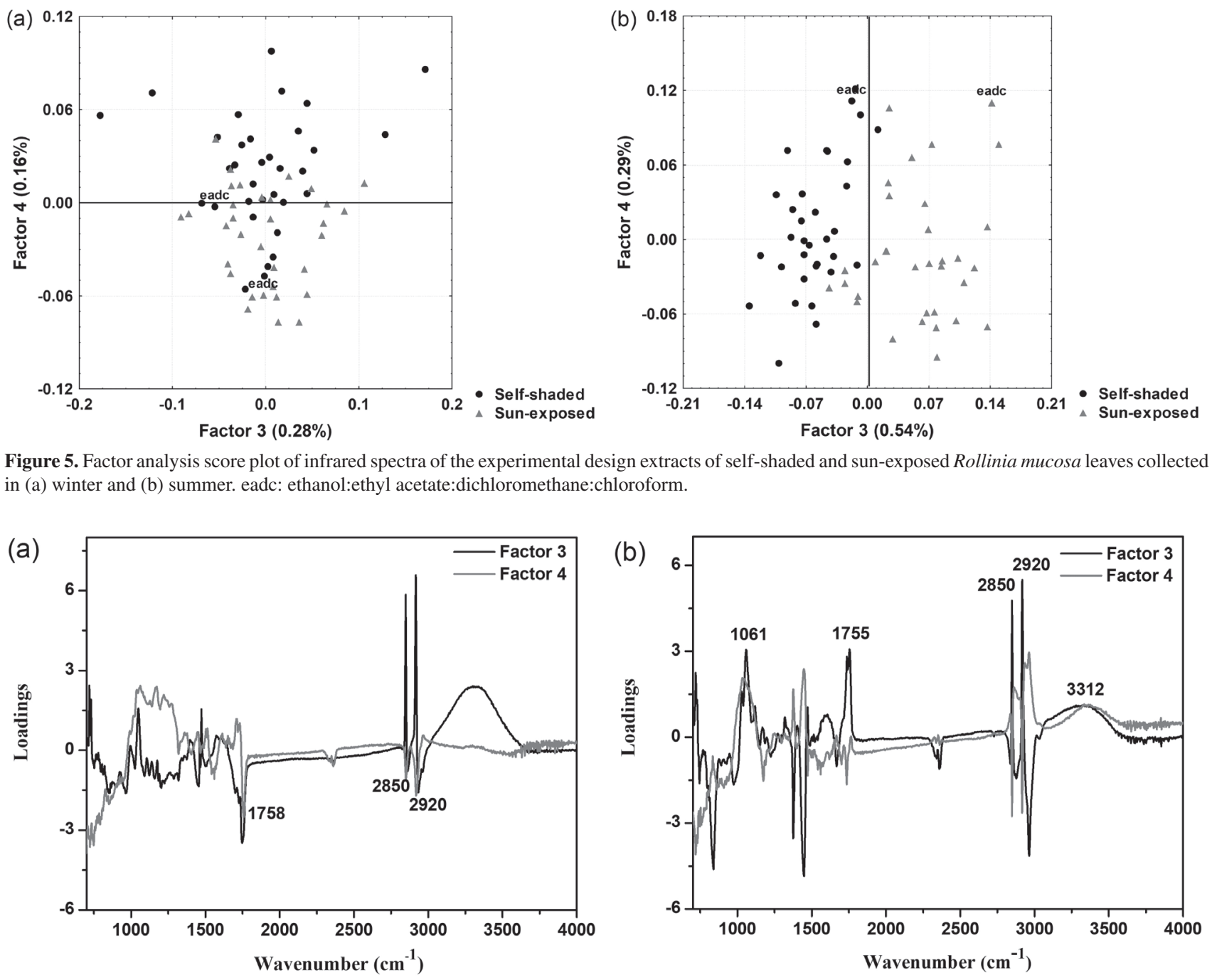

Figure 6. Factor analysis loadings of infrared spectra of self-shaded and sun-exposed leaves collected in (a) winter; (b) summer.
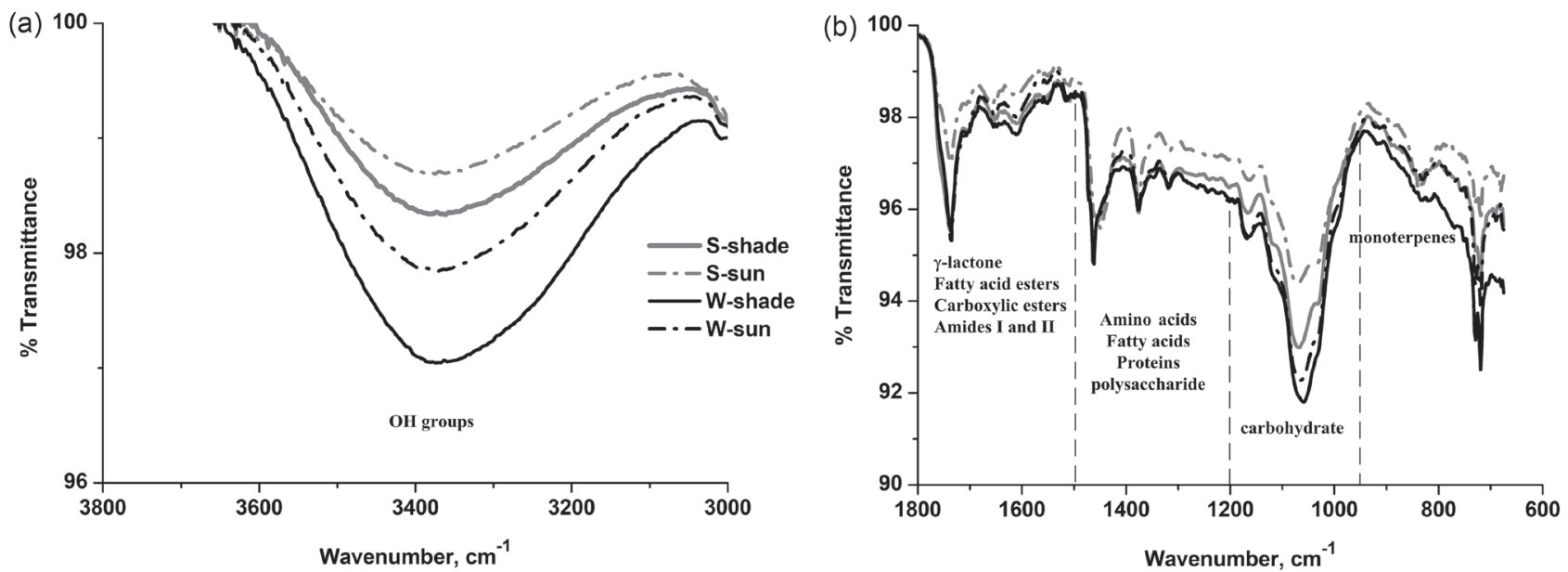

Figure 7. Average of the infrared spectra of the five solvents that presented the highest discrimination from self-shaded and sun-exposed Rollinia Mucosa leaves collected in summer and winter: (a) $3800-3000 \mathrm{~cm}^{-1}$; (b) $1800-600 \mathrm{~cm}^{-1}$. 
(a)

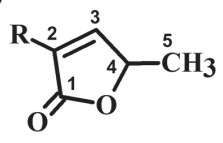

(b)

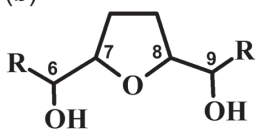

Figure 8. (a) Structure of the $\alpha, \beta$-unsaturated $\gamma$-lactone and (b) monotetrahydrofuran ring with two hydroxyls on adjacent carbons present in acetogenins.

Table 2. ${ }^{13} \mathrm{C}$ NMR data of the eadc extract of Rollinia mucosa selfshaded leaves collected in summer and of acetogenins annonacin A and annostatin (DMSO, $\delta$ )

\begin{tabular}{lccc}
\hline Position & eadc extract & Annonacin A & Aannonastatin \\
\hline 1 & 174.74 & 174.68 & 174.65 \\
2 & 131.19 & 131.14 & 131.21 \\
\hline
\end{tabular}

eadc: ethanol:ethyl acetate:dichloromethane:chloroform.

Table 3. HMQC 2D NMR contour map data of the eadc extract of the selfshaded Rollinia mисоsa leaves collected in the summer and of acetogenins annonacin A and annostatin (DMSO, $\delta$ )

\begin{tabular}{lcccccc}
\hline \multirow{2}{*}{ Position } & \multicolumn{2}{c}{ eadc extract } & \multicolumn{2}{c}{ Annonacin A } & \multicolumn{2}{c}{ Annonastatin } \\
\cline { 2 - 7 } & $\mathrm{C}$ & $\mathrm{H}$ & $\mathrm{C}$ & $\mathrm{H}$ & $\mathrm{C}$ & $\mathrm{H}$ \\
\hline 3 & 151.68 & 7.37 & 151.93 & 7.17 & 151.81 & 7.17 \\
4 & 77.93 & 5.09 & 78.03 & 5.02 & 77.99 & 5.05 \\
5 & 19.41 & 1.50 & 19.10 & 1.42 & 19.12 & 1.42 \\
6 & 73.03 & 3.26 & 71.62 & 3.40 & 74.08 & 3.40 \\
7 & 82.32 & 3.71 & 82.32 & 3.82 & 83.21 & 3.84 \\
8 & 82.05 & 3.76 & 82.31 & 3.82 & 81.82 & 3.84 \\
9 & 74.20 & 3.16 & 74.36 & 3.40 & 74.07 & 3.40 \\
\hline
\end{tabular}

eadc: ethanol:ethyl acetate:dichloromethane:chloroform.

and hydrogen atoms for comparison with the values found in the literature ${ }^{40}$ for acetogenins annonacin $\mathrm{A}$ and annostatin.

\section{Conclusions}

Fingerprinting analytical techniques, chromatographicDAD, infrared, mass spectrometric, ${ }^{1} \mathrm{H}$ and ${ }^{13} \mathrm{C}$ NMR, associated with chemometric analysis and statistical mixture design enabled the discrimination of sun-exposed and self-shaded leaves of Rollinia mucosa by identifying different chemical fingerprints for different seasons. With this experimental strategy and analytical fingerprinting it was possible to trace the different extract profiles qualitatively identifying the presence of two acetogenins, annonacin $\mathrm{A}$ and annonastatin. Infrared fingerprints show that sun-exposed and self-shaded leaves collected in summer and winter are completely different. This is important for quality control of this marketed functional food source. So analytical fingerprinting techniques

associated with chemometric methods offer an excellent tool to monitor chemical profiles of functional foods to ensure the highest concentrations of bioactive compounds taking into account seasonal as well as sunlight conditions.

\section{Acknowledgments}

The authors would like to acknowledge the NMR-UEL/ FINEP laboratory for performing the NMR analyses. This work was supported by Conselho Nacional de Desenvolvimento Científico e Tecnológico (CNPq) and Fundação Araucária, Brazilian granting agencies. CNPq is acknowledged for providing a research fellowship to I. S. S., a doctoral fellowship to S. A. and a scientific initiation scholarship to F. B. S.

\section{References}

1. Pettit, G. R.; Cragg, G. M.; Polonsky, J.; Herald, D. L.; Goswami, A.; Smith, C. R.; Moretti, C.; Schmidt, J. M.; Weisleder, D.; Can. J. Chem. 1987, 65, 1433.

2. Ferreira, L. E.; Castro, P. M. N.; Chagas, A. C. S.; França, S. C.; Beleboni, R. O.; Exp. Parasitol. 2013, 134, 327.

3. Kuo, R.-Y.; Chang, F.-R.; Chen, C.-Y.; Teng, C.-M.; Yen, H.-F.; Wu, Y.-C.; Phytochemistry 2001, 57, 421.

4. Bagavan, A.; Rahuman, A. A.; Kaushik, N. K.; Sahal, D.; Parasitol. Res. 2011, 108, 15.

5. Figueiredo, S. F. L.; Viana, V. R. C.; Simões, C.; Albarello, N.; Trugo, L. C.; Kaplan, M. A. C.; Krul, W. R.; Plant Cell, Tissue Organ Cult. 1999, 56, 121.

6. Woguem, V.; Fogang, H. P. D.; Maggi, F.; Tapondjou, L. A.; Womeni, H. M.; Quassinti, L.; Bramucci, M.; Vitali, L. A.; Petrelli, D.; Lupidi, G.; Papa, F.; Vittori, S.; Barboni, L.; Food Chem. 2014, 149, 183.

7. Osorio, E.; Arango, G. J.; Jiménez, N.; Alzate, F.; Ruiz, G.; Gutiérrez, D.; Paco, M. A.; Giménez, A.; Robledo, S.; J. Ethnopharmacol. 2007, 111, 630.

8. Costa, M. S.; Cossolin, J. F. S.; Pereira, M. J. B.; Sant'Ana, A. E. G.; Lima, M. D.; Zanuncio, J. C.; Serrão, J. E.; Toxins 2014, 6, 1169.

9. Najmuddin, S. U. F. S.; Romli, M. F.; Hamid, M.; Alitheen, N. B.; Rahman, N. M. A. N. A.; BMC Complementary Altern. Med. 2016, 16, 311.

10. Gu, Z.; Zhou, D.; Lewis, N. J.; Wu, J.; Shi, G.; McLaughlin, J. L.; Bioorg. Med. Chem. 1997, 5, 1911.

11. Chen, Y.-J.; Jin, S.; Xi, J.; Yao, Z.-J.; Tetrahedron 2014, 70, 4921.

12. Moghadamtousi, S. Z.; Rouhollahi, E.; Karimian, H.; Fadaeinasab, M.; Firoozinia, M.; Abdulla, M. A.; Kadir, H. A.; PLoS One 2015, 10, e0122288.

13. Liu, H.-X.; Huang, G.-R.; Zhang, H.-M.; Wu, J.-R.; Yao, Z.-J.; Bioorg. Med. Chem. Lett. 2007, 17, 3426. 
14. Zafra-Polo, M. C.; González, M. C.; Estornell, E.; Sahpaz, S.; Cortes, D.; Phytochemistry 1996, 42, 253.

15. Defaveri, A. C. A.; Sato, A.; Borré, L. B.; Aguiar, D. L. M.; Gil, R. A. S. S.; Arruda, R. C. O.; Riehl, C. A. S.; J. Braz. Chem. Soc. 2011, 22, 1531.

16. Barbosa, Q. P. S.; da Câmara, C. A. G.; Ramos, C. S.; Nascimento, D. C. O.; Lima-Filho, J. V.; Guimarães, E. F.; Quim. Nova 2012, 35, 1806.

17. Klein, F. R. S.; Reis, A.; Kleinowski, A. M.; Telles, R. T.; do Amarante, L.; Peters, J. A.; Braga, E. J. B.; Acta Bot. Bras. 2018, 32, 615 .

18. Gobbo-Neto, L.; Lopes, N. P.; Quim. Nova 2007, 30, 374.

19. Pearcy, R. W.; Muraoka, H.; Valladares, F.; New Phytol. 2005, 166, 791.

20. Hussain, A. I.; Anwar, F.; Nigam, P. S.; Ashraf, M.; Gilani, A.; J. Sci. Food Agric. 2010, 90, 1827.

21. Passari, L. M. Z. G.; Scarminio, I. S.; Marcheafave, G. G.; Bruns, R. E.; Food Chem. 2019, 273, 151.

22. March, R. H.; Clark, L. G.; Telopea 2011, 13, 93.

23. Kruger, N. J.; Troncoso-Ponce, M. A.; Ratcliffe, R. G.; Nat. Protoc. 2008, 3, 1001.

24. Hatumura, P. H.; de Oliveira, G. S.; Marcheafave, G. G.; Rakocevic, M.; Bruns, R. E.; Scarminio, I. S.; Terrile, A. E.; Food Anal. Methods 2018, 11, 1906.

25. Schiozer, A. L.; Cabral, E. C.; de Godoy, L. A. F.; Chaves, F. C. M.; Poppi, R. J.; Riveros, J. M.; Eberlin, M. N.; Barata, L. E. S.; J. Braz. Chem. Soc. 2012, 23, 409.

26. Delaroza, F.; Rakocevic, M.; Malta, G. B.; Bruns, R. E.; Scarminio, I. S.; J. Braz. Chem. Soc. 2014, 25, 1929.

27. Guizellini, F. C.; Marcheafave, G. G.; Rakocevic, M.; Bruns, R. E.; Scarminio, I. S.; Soares, P. K.; Food Res. Int. 2018, 113, 9.

28. Soares, P. K.; Marcheafave, G. G.; Gomes, A. A.; Scarminio, I. S.; Bruns, R. E.; Chromatographia 2018, 81, 1189.

29. Terrile, A. E.; Marcheafave, G. G.; Oliveira, G. S.; Rakocevic, M.; Bruns, R. E.; Scarminio, I. S.; J. Braz. Chem. Soc. 2016, 27, 1254.
30. Afonso, S.; de Matos, A. C.; Marengo, V. A.; Moreira, E. G.; Soares, D. X.; Koolen, H. H. F.; Scarminio, I. S.; J. Braz. Chem. Soc. 2015, 26, 350.

31. Afonso, S.; Pisano, P. L.; Silva, F. B.; Scaminio, I. S.; Olivieri, A. C.; J. Braz. Chem. Soc. 2015, 26, 2241.

32. Garcia, L. M. Z.; Pauli, E. D.; Cristiano, V.; da Camara, C. A. P.; Scarminio, I. S.; Nixdorf, S. L.; J. Chromatogr. Sci. 2009, 47,825 .

33. Soares, P. K.; Scarminio, I. S.; Phytochem. Anal. 2008, 19, 78.

34. Borges, C. N.; Bruns, R. E.; Almeida, A. A.; Scarminio, I. S.; Anal. Chim. Acta 2007, 595, 28.

35. Garcia, L. M. Z.; de Oliveira, T. F.; Soares, P. K.; Bruns, R. E.; Scarminio, I. S.; Chemom. Intell. Lab. Syst. 2010, 103, 1.

36. Bruns, R. E.; Scarminio, I. S.; Neto, B. B.; Statistical Design - Chemometrics, $1^{\text {st }}$ ed.; Elsevier: Amsterdam, 2006.

37. de Souza, E. B. R.; da Silva, R. R.; Afonso, S.; Scarminio, I. S.; J. Sep. Sci. 2009, 32, 4176.

38. Statistica, version 6.0; StatSoft, Tulsa, OK, USA, 2001.

39. Prayitno, A.; Artanti, A. N.; Dewangga, V. S.; Abdullah, I.; Hartati, M.; Fitria, M. S.; Elmanda, A. Y.; Astirin, O. P.; Immunome Res. 2016, 12, 120.

40. Rupprecht, J. K.; Hui, Y.-H.; Mclaughlin, J. L.; J. Nat. Prod. 1990, 53, 237.

41. Chen, Y.; Xu, S.; Chen, J.; Wang, Y.; Xu, H.; Fan, N.; Li, X.; J. Ethnopharmacol. 2012, 142, 462.

42. Afonso, S.; Silva, F. B.; Silva, A. F.; Scarminio, I. S.; Bruns, R. E.; J. Mol. Struct. 2017, 1130, 174.

43. Robert, P.; Devaux, M. F.; Qannari, A.; Safar, M.; J. Near Infrared Spectrosc. 1993, 1, 99.

Submitted: September 6, 2018 Published online: December 13, 2018 